OPEN ACCESS

Edited by:

Marta Bienkiewicz,

Aix-Marseille University, France

Reviewed by:

James Shine,

Brain and Mind Research Institute,

Australia

Lawrence Mitchell Parsons,

University of Sheffield, UK

*Correspondence:

Madeleine E. Hackney

mehack@emory.edu

Specialty section:

This article was submitted to Movement Disorders, a section of the

journal Frontiers in Neurology

Received: 16 September 2015

Accepted: 16 November 2015

Published: 02 December 2015

Citation:

Hackney ME, Lee HL, Battisto J, Crosson B and McGregor KM (2015) Context-Dependent Neural Activation:

Internally and Externally Guided

Rhythmic Lower Limb Movement in Individuals With and Without Neurodegenerative Disease. Front. Neurol. 6:251. doi: 10.3389/fneur.2015.00251

\section{Context-Dependent Neural Activation: Internally and Externally Guided Rhythmic Lower Limb Movement in Individuals With and Without Neurodegenerative Disease}

\author{
Madeleine E. Hackney ${ }^{1,2 *}$, Ho Lim Lee ${ }^{3}$, Jessica Battisto ${ }^{3}$, Bruce Crosson ${ }^{1,4}$ and \\ Keith M. McGregor ${ }^{1,4}$

\begin{abstract}
Atlanta VA Center for Visual and Neurocognitive Rehabilitation, Decatur, GA, USA, ${ }^{2}$ Division of General Medicine and Geriatrics, Department of Medicine, Emory School of Medicine, Atlanta, GA, USA, ${ }^{3}$ Emory College of Arts and Sciences,
\end{abstract} \\ Emory University, Atlanta, GA, USA, ${ }^{4}$ Department of Neurology, Emory School of Medicine, Atlanta, GA, USA
}

Parkinson's disease is a neurodegenerative disorder that has received considerable attention in allopathic medicine over the past decades. However, it is clear that, to date, pharmacological and surgical interventions do not fully address symptoms of PD and patients' quality of life. As both an alternative therapy and as an adjuvant to conventional approaches, several types of rhythmic movement (e.g., movement strategies, dance, tandem biking, and Tai Chi) have shown improvements to motor symptoms, lower limb control, and postural stability in people with PD (1-6). However, while these programs are increasing in number, still little is known about the neural mechanisms underlying motor improvements attained with such interventions. Studying limb motor control under task-specific contexts can help determine the mechanisms of rehabilitation effectiveness. Both internally guided (IG) and externally guided (EG) movement strategies have evidence to support their use in rehabilitative programs. However, there appears to be a degree of differentiation in the neural substrates involved in IG vs. EG designs. Because of the potential task-specific benefits of rhythmic training within a rehabilitative context, this report will consider the use of IG and EG movement strategies, and observations produced by functional magnetic resonance imaging and other imaging techniques. This review will present findings from lower limb imaging studies, under IG and EG conditions for populations with and without movement disorders. We will discuss how these studies might inform movement disorders rehabilitation (in the form of rhythmic, music-based movement training) and highlight research gaps. We believe better understanding of lower limb neural activity with respect to $P D$ impairment during rhythmic IG and EG movement will facilitate the development of novel and effective therapeutic approaches to mobility limitations and postural instability.

Keywords: lower limb, motor control, neuroimaging, rhythm, externally cued, internally guided, Parkinson's disease 


\section{REHABILITATION IN PARKINSON'S DISEASE}

Pharmacology and surgery do not fully address the motor, cognitive, and psychosocial needs of those with Parkinson's disease (PD), a neurodegenerative disorder that is related to dopamine depletion in the substantia nigra pars compacta, which in turn hinders processing in the basal ganglia (7). Several mobility programs are effective (e.g., mobility training, dance, tandem biking, and Tai Chi) for improving motor symptoms, lower limb control, and postural stability in people with PD (2-6). These programs use a mixture of internally guided (IG) and externally guided (EG) movement strategies, both of which have evidence to support their use in rehabilitative scenarios. However, little is known about rhythmic lower limb movement relating to locus of cue (EG vs. IG). Many rehabilitative programs preferentially select one locus over another, which may or may not be optimal for long-term improvement of mobility. Better mechanistic understanding of beneficial exercise effects on neural circuitry garnered under specific contexts could improve the design of motor rehabilitation interventions for particular symptoms (e.g., freezing and bradykinesia) and the various disease stages of $\mathrm{PD}$.

The goal of this review is to provide rehabilitative specialists and researchers with the state of the rehabilitation science regarding the potential neural underpinnings of IG and EG movements. Respective of this, IG movement neural dynamics will be contrasted with those of EG movements. As implemented, the dichotomy provided in this review respective of movement locus of cue is didactically necessary but practically difficult to realize from a rehabilitative perspective. Ecologically speaking, human movement is rarely, if ever, purely IG or EG, whether in the case of daily activities or in rehabilitative settings. That said, determining the beneficial and most effective qualities and outcomes of IG and EG motor training could inform rehabilitation particularly for largely intractable conditions like PD.

\section{INTERNALLY GUIDED MOVEMENT IN REHABILITATION}

Proper completion of IG movements relies on efficient function of subcortical loops involving the basal ganglia $(8,9)$. Due to dysfunction of the striato-thalamo-cortical (STC) circuit [also referred herein as the cortico-basal-ganglia-thalamic (CBGT)], people with PD have particular difficulty with IG tasks (10-12). However, this impairment can be remediated by motor rehabilitation that uses skills in which participants engage cognitively in planning and selecting movements (5). Specifically for individuals with $\mathrm{PD}$, having complex movements broken down into simpler elements may facilitate motor performance. Employing a "movement strategy" that demands increased focus on movement plans and mentally rehearsing and/or preparing for selfinitiated movement may be helpful. For example, focusing on critical movement aspects (e.g., longer steps, quicker movements) helps individuals with PD to achieve nearly normal speed and amplitude (13). Thus, IG training may be helpful for individuals with PD.

\section{EXTERNALLY GUIDED MOVEMENT IN REHABILITATION}

Abundant evidence also demonstrates benefits of rehabilitative exercise that exploits external cueing, which likely specifically targets neural systems that support balance $(4,14)$. EG strategies have improved movement initiation $(15,16)$. Other research has shown that people with PD have faster reaction times when externally cued compared to self-initiated (IG) movement (17). Synchronizing movement to rhythmic beats provided externally may enhance movement speed (18). There is also a well-known facilitating effect of cues for alleviating freezing of gait (FOG) (19). Furthermore, gait training with regular external rhythmic auditory cues has improved gait velocity, stride length, step cadence, timing of EMG patterns, and mobility in persons with PD (20-22). Evidence has begun to accumulate that suggests external cues access alternate neural pathways that remain intact in the individuals with $\mathrm{PD}$, including the cerebellar-thalamo-cortical (CTC) network.

\section{CHARACTERIZATION OF THE NEURAL CIRCUITRY INVOLVED WITH INTERNALLY AND EXTERNALLY GUIDED MOVEMENT}

This review covers available literature focused on imaging studies involving IG and EG upper and lower limb movement paradigms within the contexts of cortical and subcortical neural function. Our goal is to summarize findings from the available lower limb literature to inform future research with goals of characterizing neural areas involved in motor rehabilitation of PD. Numerous neural systems likely produce IG and EG movement and could be modulated by rehabilitative training. However, the current work is not intended to provide an encyclopedic reference to neural network function in motor systems, although we provide a reference in Table 1 that catalogs a number of studies that involve IG and EG paradigms. Rather we will focus on the neural routes that likely assume multiple subcomponents to be explicated in future rehabilitation research. These routes are (a) cortically modulated (mainly in the frontal and parietal lobes), (b) subcortically modulated including the basal ganglia and thalamus, and (c) the cerebellum.

In the neurotypical model, the investigation of IG and EG movements of the upper extremity has received considerable attention in neuroimaging $(41,46,49,51,52)$. These studies have suggested distinct cortico-cerebellar, cortico-cortico, and corticosubcortical neural pathways for IG vs. EG in a variety of contexts. The following sections will address differences between neural activity from both a region of interest (ROI) and neural network perspective. It needs to be noted that a vast majority of motor-related literature with such a focus has been done in upper extremity movements. Given the relatively young science of neuroimaging, this is somewhat understandable as there are considerable technical difficulties in controlling motion being translated from the legs to the head during movement. As such, studies investigating neural correlates of movements of the lower extremity in humans in the context of IG vs. EG control are rare. We will attempt to address the differences between upper extremity movements and lower extremity movements as available 


\begin{tabular}{|c|c|c|c|c|c|}
\hline Reference & $\begin{array}{l}\text { Population and } N \text { : (young } \\
<40 \text { years; older }>50 \text { years) }\end{array}$ & $\begin{array}{l}\text { Internally guided or } \\
\text { externally guided }\end{array}$ & $\begin{array}{l}\text { Upper or lower } \\
\text { limb movement }\end{array}$ & Task & Finding \\
\hline (23) & 12 Healthy young & $E G$ & Lower limb & $\begin{array}{l}\text { Imagery and execution of } \\
\text { ankle dorsiflexion }\end{array}$ & $\begin{array}{l}\text { EG movement execution and motor imagery shared a common network, including the } \\
\text { premotor, parietal and cingulate cortices, the striatum, and the cerebellum }\end{array}$ \\
\hline (24) & $\begin{array}{l}4 \text { Hemiparetic vs. } 12 \text { healthy } \\
\text { subjects ( } 25-70 \text { years) }\end{array}$ & $E G$ & Lower limb & Ankle dorsiflexion & EG-guided hemiparetic \\
\hline (25) & $\begin{array}{l}20 \text { PD patients; } 10 \text { healthy } \\
\text { (non-age matched) }\end{array}$ & $E G$ & Lower limb & Ankle dorsiflexion & $\begin{array}{l}\text { PD-off: precentral gyrus, supplementary area, parietal opercular cortex, and ipsilateral } \\
\text { cerebellum activated; PD-on: similar activation pattern as off, with additional activation of } \\
\text { insular cortex; healthy-off: contralateral precentral gyrus, central opercular, cortex, and } \\
\text { ipsilateral cerebellum; healthy-on: activations in precentral gyrus, central and parietal } \\
\text { opercular cortex, cerebellum, and posterior cingulate cortex - no sig. increased activation } \\
\text { in on vs. off for controls }\end{array}$ \\
\hline (26) & 8 Healthy (25-57 years) & $E G$ & Lower limb & $\begin{array}{l}\text { Ankle dorsiflexion vs. } \\
\text { plantarflexion }\end{array}$ & EG dorsiflextion activated from medial M1S1 to SMA \\
\hline (27) & 16 Healthy young & $E G$ & Lower limb & $\begin{array}{l}\text { Ankle dorsiflexion vs. } \\
\text { plantarflexion }\end{array}$ & $\begin{array}{l}\text { Both right and left ankle active movements activated SMA, contralateral M1, and primary } \\
\text { somatosensory cortex (SI) }\end{array}$ \\
\hline (28) & 13 PD, 13 age-matched healthy & IG & Lower limb & Gait imagery & $\begin{array}{l}\text { During imagined movement, right dorsal premotor area (PMd), precentral, right inferior } \\
\text { parietal lobule, and bilateral precuneus were more activated in PD compared to } \\
\text { age-matched controls }\end{array}$ \\
\hline (29) & 18 Healthy young & $I G$ and $E G$ & Lower limb & $\begin{array}{l}\text { Ankle dorsiflexion with and } \\
\text { without visual cue }\end{array}$ & $\begin{array}{l}\text { IG ankle movements has distinct network comprising the posterior parietal cortex and } \\
\text { lateral cerebellar hemispheres }\end{array}$ \\
\hline (30) & 16 Healthy young & $E G$ & $\begin{array}{l}\text { Upper and } \\
\text { lower limbs }\end{array}$ & Wrist and ankle flexion & Lower extremity EG more bilaterally active than upper extremity EG \\
\hline (31) & 24 Healthy young & $E G$ & $\begin{array}{l}\text { Upper and } \\
\text { lower limbs }\end{array}$ & Foot and finger movement & $\begin{array}{l}\text { Relative overlap of cortical recruitment in M1 and SMA for lower extremity and upper } \\
\text { extremity movements }\end{array}$ \\
\hline (32) & 23 Healthy young & IG & $\begin{array}{l}\text { Upper and } \\
\text { lower limbs }\end{array}$ & $\begin{array}{l}\text { Adduction and abduction of } \\
\text { finger vs. adduction and } \\
\text { abduction of foot }\end{array}$ & Cerebellum: overlap of activations for foot and finger movement \\
\hline (33) & $\begin{array}{l}17 \text { Healthy young, } 21 \text { healthy } \\
\text { older }\end{array}$ & IG & $\begin{array}{l}\text { Upper and } \\
\text { lower limbs }\end{array}$ & Hand and foot flexion & $\begin{array}{l}\text { Older adults recruited a more elaborate network of motor and non-motor regions younger } \\
\text { adults }\end{array}$ \\
\hline (34) & 13 Healthy young & $I G$ and $E G$ & $\begin{array}{l}\text { Upper and } \\
\text { lower limbs }\end{array}$ & Finger vs. toe flexion & $\begin{array}{l}\text { Finger and toe movements showed differential cerebellar recruitment; more bilateral during } \\
\text { complex tasks }\end{array}$ \\
\hline (35) & 11 Healthy young & $E G$ & Upper limb & Hand force production & Caudate nucleus is involved in planning motor force, but not force execution in EG tasks \\
\hline (36) & 10 Healthy young & $E G$ & Upper limb & $\begin{array}{l}\text { Finger button press and } \\
\text { motor imagery }\end{array}$ & Cognitive and motor processes activate segregated areas of the cerebellum \\
\hline (37) & 9 Healthy young & $E G$ & Upper limb & Finger tapping & EG finger tapping recruited cerebellum: right lobules IV-V and right lobules VIIIA and VIIIB \\
\hline (38) & 7 Healthy young & $E G$ & Upper limb & Finger button press & $\begin{array}{l}\text { Finger specific BOLD patterns showed overlapping sensory and motor representations in } \\
\text { cerebellum }\end{array}$ \\
\hline (39) & 11 Healthy young & $E G$ & Upper limb & Hand force production & Only the caudate nucleus increased activation when the subjects mapped force \\
\hline (40) & 10 PD; 10 age-matched healthy & $E G$ & Upper limb & Hand force modulation & $\begin{array}{l}\text { Off medication PD subjects have novel area recruitments of the bilateral cerebellum and } \\
\text { primary motor cortex as compared to healthy adults }\end{array}$ \\
\hline (41) & 10 Healthy young & $I G$ and $E G$ & Upper limb & Drawing vs. tracing with hand & $\begin{array}{l}\text { Results indicated that compared to tracing }(E G) \text {, drawing }(I G) \text { generated greater activation } \\
\text { in the right cerebellar crus I, bilateral pre-SMA, right dorsal premotor cortex, and right } \\
\text { frontal eye field }\end{array}$ \\
\hline
\end{tabular}

certex, and ipsiateral cerebellum; healthy-on: activations in precentral gyrus, central and parietal in on vs. off for controls

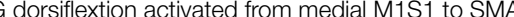
somatosensory cortex (S)

During imagined movement, right dorsal premotor area (PMd), precentral, right inferior age-matched controls

IG ankle movements has distinct network comprising the posterior parietal cortex and lateral cerebellar hemispheres

Relative overlap of cortical recruitment in M1 and SMA for lower extremity and upper extremity movements finger vs. adduction and abduction of foot

Older adults recruited a more elaborate network of motor and non-motor regions younger adults Caudate nucleus is involved in planning motor force, but not force execution in EG tasks EG finger tapping recruited cerebellum: right lobules IV-V and right lobules VIIIA and VIIIB Finger specific BOLD patterns showed overlapping sensory and motor representations in cerebellum primary motor cortex as compared to healthy adults in the right cerebellar crus I, bilateral pre-SMA, right dorsal premotor cortex, and right 


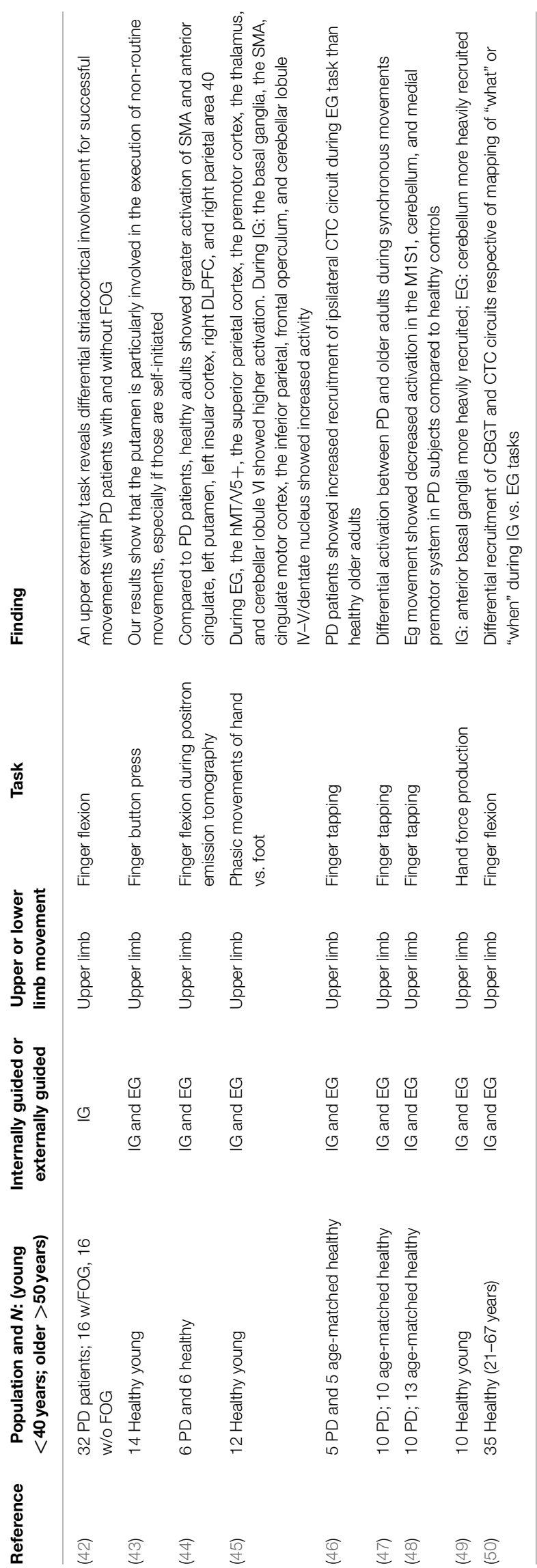

literature can inform. However, the scarcity of data involving lower extremity movements does not afford us a complete understanding of the potential variability explained by contrasting upper vs. lower limb movements. While Keele et al. (53) demonstrated that finger tapping, forefoot tapping, and heel tapping are highly correlated in light of timing mechanisms (53), differences between hand and foot movements in functional brain anatomy have been reported in imaging studies (54, 55). An important example of these differences was recently reported by Volz et al. (30) who used functional magnetic resonance imaging (fMRI) to assess cortical network function in younger adults performing unimanual hand or foot tapping. The authors reported significant differences in premotor connectivity with hand movements having a much stronger cortical representation in the motor planning areas. Additionally, upper extremity performance appears to be highly lateralized as compared to lower limb movements. With respect to disease models, the examination of motor control in conditions like PD has largely focused on upper limb control. Respective of this, where applicable and available, we will attempt to differentiate reports involving lower extremity from upper extremity research (Figure 1).

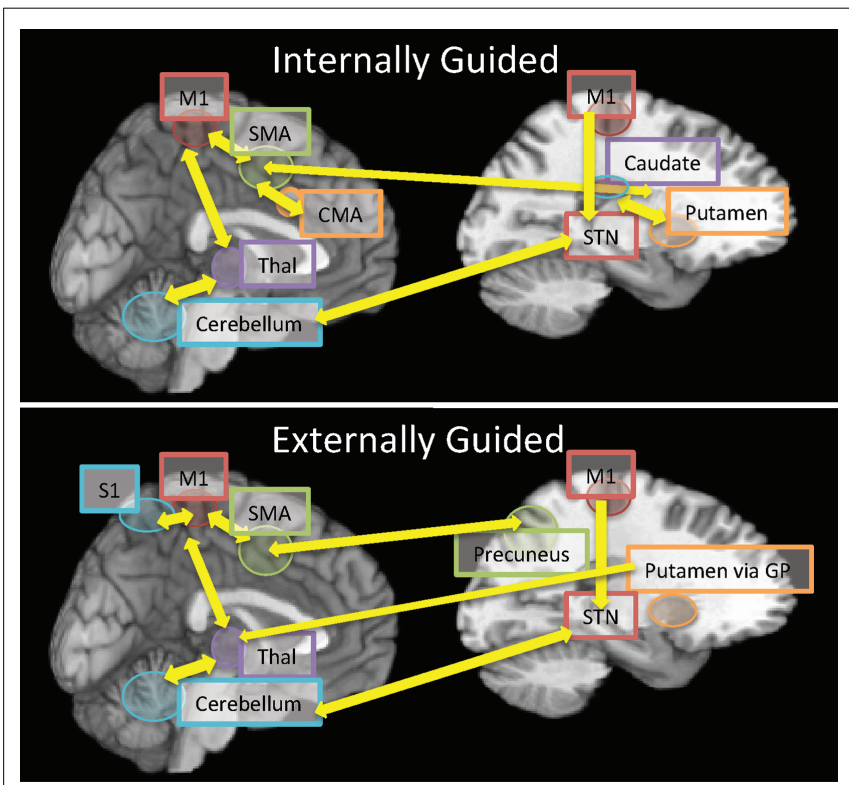

FIGURE 1 | A representative synopsis of the connectivity reported in the current review comparing neural connectivity in internally guided vs. externally guided movements. The top panel represents connectivity within internally guided movements whose initiation from cortical regions (SMA, M1, and CMA) is mediated by the striatum (caudate for movement selection; putamen for execution) and thalamo-cerebellar bidirectional processing for movement execution. By contrast, the bottom panel represents connectivity during externally guided movements, which originate from sensorimotor integration (M1S1, SMA, and precuneus) due to the external cue for initiation. The progression of motor execution engages the lentiform nuclei (putamen, GP), which then influence cortico-thalamocerebellar processing during task execution. Abbreviations: SMA, supplementary motor area; M1, primary motor cortex; S1, primary somatosensory cortex; STN, subthalamic nucleus; CMA, cingulate motor area; GP, globus pallidus; Thal, thalamus. 


\section{INTERNALLY GUIDED NEURAL CIRCUITRY - CORTICAL, SUBCORTICAL, AND PD}

\section{Cortical Activity}

Cortical initiation of IG movements has received a fair amount of study with neuroimaging over the past 20 years. Prior to this, based on primate models, the role of the supplementary motor cortex (SMA) was considered crucial to the initiation of IG movements. Single unit recordings of neurons in macaque SMA showed greater spiking during IG movements rather than those prompted by external cues, which were thought to involve premotor areas (rostral to the anterior commissure in BA6) $(56,57)$. However, as our understanding of neural circuits improved with neural pathway tracings in primates, anatomical differentiation of these regions informed the functional distinction of premotor cortex, pre-SMA, and SMA $(58,59)$. When neuroimaging techniques were applied to probe the anatomical substrates involving IG movements, a much different picture with respect to cortical involvement emerged. Multiple labs used fMRI during upper extremity tasks to identify cortical activity during IG movement paradigms and found that the SMA (medial BA6, posterior to the anterior commissure) was not significantly driving the execution of movements in IG conditions $(49,60)$. Instead, there was a strong influence of a complex cortical and subcortical initiation and gating network that has since been largely confirmed by network-based modeling analysis $(39,50)$. Moreover, recent work has identified functionally distinct networks respective of the timing of the IG movements with alteration of cortico-basal ganglia involvement during initiation and then execution of the movement. During movement initialization (i.e., the process of identification/selection of motor responses), the anterior cingulate motor area (which may be considered an extension of pre-SMA) and pre-SMA appear to be critically involved as their damage results in improper suppression of selected motor responses $(50,61)$. However, the transition into direct engagement of skeletal muscle recruits additional cortical resources including lateral BA6, inferior parietal regions, and lateral inferior frontal areas (Broca's area - left BA44) (62). This lateral frontal recruitment could be interpreted as selective movement organization, as Broca's area is crucial for proper syntactic discourse $(63,64)$. For example, in the English language, syntax is heavily dependent on word order, and even more so in German. Broca's area is critical in identifying the sequential order of word placement (63). In an analogous motor role, activation in Broca's area may indicate order selection for organized movement (65).

\section{Subcortical}

The cortical components of IG are strongly gated and in some cases are dependent on reciprocal input from subcortical structures, primarily the striatum. The caudolenticular gray bridges, topographically interposed between the caudate and the putamen, function as the primary efferent center from pre-SMA to the basal ganglia (66). As such, the striatum plays a critical role in modulating movement, and its activity is largely dependent on movement state. A functional dichotomy exists between caudate and putamen activity during IG movements. The caudate is linked to motor learning and sensory processing of proprioceptive input in this context $(52,67)$. Vaillancourt et al. (39) reported on IG force production at different levels during fMRI (39). Interestingly, the caudate was selectively activated only during the process of identifying and selecting the proper force to produce. Later, the group exquisitely showed that the caudate was selectively engaged in the processing of force for production but did not activate during force production (35). As such, the caudate is likely directly involved in the mapping of higher cortical motor process [input to the gray bridges is through premotor, SMA and M1 connectivity in IG movements (68)]. However, the caudate does not appear to assist in timing of IG movement execution. Instead, this function appears to be fulfilled by the putamen.

Many imaging studies have probed the function of the putamen and its role in timing of IG movements. For years, this structure has been reported as active during execution of IG tasks using fMRI $(9,35,39,49,67,69)$. Recently, these reports have been informed by alternate modalities indicating the neural timing of activity in the putamen with respect to regulation of IG movement. Using local field potential (LFP) recordings in macaques, Bartolo et al. recently investigated tuning of spiking potentials respective of movement state, either EG or IG cued (70). While the putamen is involved in both types of activity, the waveforms of the spike potentials tuned differentially to the locus of cue. These waveforms were characterized by frequency consisting of beta $(13-30 \mathrm{~Hz})$ and gamma frequencies $(30-70 \mathrm{~Hz})$ and were compared during the execution of IG and EG tasks. IG movements were strongly aligned with the beta band of the LFPs. Alternately, during EG movements, LFP activity was characterized by gamma frequency oscillations. Importantly, when sampling across larger distances the beta frequency coherence was high indicating a possible functional coordination of the putamen during IG tasks. Conversely, the spatial coherence of gamma frequencies was very low, which could be interpreted to indicate local, single event processing $(70,71)$. The authors concluded that the gamma frequency activity potentially indicated local computations directly related to external stimulus processing. In contrast, the beta band preference in the putamen was the result of a larger scale entrainment of CBGT circuits as these were associated with IG movement timing. The authors provided additional evidence for this in a recent paper investigating LFP oscillations during different task types (reaction time vs. internally timed tapping) (72).

\section{Cerebellum}

Although we have thus far focused on the STC circuit in its role for IG movement, the cerebellum has been implicated in IG movement as well. While this may be surprising given the literature recognizing cerebellar involvement in explicitly EG tasks $(41,45,47$, $60,73)$, IG tasks have been reported to recruit cerebellar regions. fMRI studies involving IG movements of the upper extremity have reported regional recruitment of cerebellum, including lobulus $\mathrm{V}$ (anterior cerebellum) and lobules VIIB and VIII (inferior cerebellum) (74). During arm pointing movements (using both left and right arms), activations were found ipsilateral to movement in lobule V and lobule VIIA (34). While studies employing lower 
extremity movement during IG tasks are scarce, a study from Schlerf et al. (34), in which they attempted to characterize cerebellar activity during IG upper and lower extremity movements, is worth noting. The group investigated differential cerebellar involvement when modulating task difficulty of both the upper and lower extremities (fingertip and toe, respectively). Toe tapping activated more anterior areas of the cerebellum compared to finger movements regardless of movement difficulty. Interestingly, the group also found greater bilateral cerebellar activity during more difficult lower extremity movements compared to analogously difficult conditions during finger tapping. Other groups have further investigated the possibly differential cerebellar representations of lower limb movement as contrasted to upper extremity movement. A recent study by Kuper et al. (32) aimed to identify overlapping or distinct cerebellar activity when contrasting finger and foot tapping at the joints' maximum movement range (32). Interestingly, while overlapping cerebellar finger and foot activity were present [cf., Ref. (34)], Kuper et al. found activity appeared to follow a somatotopy with foot activation occurring more rostrally compared to finger movement.

However, the attribution of cerebellar recruitment with respect to IG vs. EG locus of cue is incomplete without proper conceptualization of timing within a movement context. In a recent consensus paper (75), Richard Ivry denoted an important qualifier of cerebellar activity respective of movement timing, by noting that much work using imaging of the cerebellum has difficulty teasing apart externally cued movement and its transition to emergent timing. The difficulty is partially explained by the challenge that lies in differentiating absolute time vs. perceived time and the role that the cerebellum plays in optimizing the coordination of the two. Taken in this light, the role of cerebellar recruitment during IG vs. EG movement becomes somewhat mottled in the imaging literature. What may be deemed "internally guided" may be continuously informed by an emergent timing within the participant when this individual is trying to synchronize internal timing to his/her perception of absolute timing.

\section{INTERNALLY GUIDED MOVEMENT IN PARKINSON'S DISEASE}

As PD is caused by the loss of endogenous dopamine, the disease profoundly affects basal ganglia function. The most immediate impact of dysfunction in IG movement in PD relates to impaired cortico-basal ganglia communication driving initiation of movement. One such behavioral manifestation of this disruption is the presence of bradykinesia in PD during IG movement (76). As stated above, cortical initiation of IG movements relies on basal ganglia modulation (particularly at the striatofrontal interconnect at the post-commisural putamen) and signal augmentation that is highly sensitive to disruption when filtered through dysfunctional lentiform connections (77). However, this physiology is complicated by the importance of sensory feedback required for proprioception and kinesthetic integration. These afferent inputs are directly modulated by thalamo-cortical relays involving the subthalamic nucleus, ventrolateral, and centromedian thalamic nuclei $(68,78,79)$. As such, disruption of the sensory integration back to motor planning cortex further complicates successful movement initiation by disruption of physical state monitoring required for movement.

Deficient gating of sensory signals in the basal ganglia (80) may lead to abnormal processing of proprioceptive input in motor regions, such as the SMA (81). In a related study, Goble et al. (82) examined how brain activity resulting from stimulation of proprioceptors is related to performance in a proprioceptorrelated task (82). Subjects lying in an fMRI scanner received vibrations on their foot, allowing for proprioceptive brain mapping via muscle spindle stimulation. Exposure to foot vibrations showed an association of the basal ganglia structures with structures involved in postural control. Movement studies show the basal ganglia play a significant role in motor learning. In a study by Jueptner and Weiller, positron emission tomography (PET) measurements of regional cerebral blood flow (rCBF) were used for studies of motor learning, visuomotor coordination, and sensory movement control (9). Furthermore, the basal ganglia have been shown to be involved in controlling ongoing movements, including feedback processing (83). Maschke et al. examined the role of the basal ganglia in kinesthesia, the conscious awareness of limb position, with a passive elbow movement task in participants with $\mathrm{PD}$, participants with spinocerebellar ataxia (SCA), and age-matched healthy control participants. The PD participants showed significant kinesthetic deficit to control participants, whereas the SCA participants showed no kinesthetic deficit, allowing the conclusion that CBGT loops are important in kinesthesia (84).

Symptoms associated with PD provide some insight into the disease process on neural circuits and inform rehabilitation strategies of lower limb-related problems. FOG is a common and dangerous condition in individuals with PD whereby the person successfully initiates walking, but it is transiently unable to complete the gait cycle, frequently resulting in imbalance and increased fall risk. FOG is functionally distinct from bradykinesia and postural rigidity and is only conditionally affected by pharmacological treatment $(85,86)$. Although FOG is challenging to characterize as EG or IG, we will consider FOG a failure to continue a self-initiated movement, the primary manifestation of the condition. FOG very likely represents a disrupted sense of internal rhythmic timing (87). Peterson et al. (88) informed upon the brain regions that are involved in PD patients with and without FOG. In this study, PD patients imagined walking during fMRI acquisition. The results showed significantly lower activity in supplementary motor regions, globus pallidus, and cerebellum in individuals with PD who experience FOG compared to those who did not report FOG. Furthermore, the authors reported decreased activity in the mesencephalic regions associated with postural stability (88). These widespread activity differences between groups indicate that individual discrete neural circuits do not easily account for the motor dysfunction exhibited by FOG. Rather, cortical, subcortical, and cerebellar loops are all affected in FOG. This finding may explain the large variability of pharmacological and surgical outcomes relating to FOG in PD $(85,86,89)$. Importantly, this study indicates rehabilitative strategies that are focused on IG movements need to be holistic in approach because no single sub-circuit or structure is preferentially involved in these movements. 


\section{EXTERNALLY GUIDED NEURAL CIRCUITRY - CORTICAL, CEREBELLAR, AND PD}

Externally guided movements involve both overlapping and discrete brain regions for successful task completion. While studies vary widely in terms of the methodology employed, externally cued movement of differing types involves similar cortical, subcortical, and cerebellar substrates. We will explore these areas as they are associated with EG movements and discuss how PD may disrupt proper execution with implications for rehabilitation programs to follow.

\section{Cortical Involvement in EG Movement}

Prior to modern neuroimaging, the initial cortical origin of IG movements was thought to be SMA (57), as cortical activity in EG was viewed in the context of the motor planning and, as such, focused on the relationship between premotor areas with primary motor cortex (90-92). This work in the non-human primate model still provides invaluable insight into cortical function, but it has been updated in the human model with functional neuroimaging. The following text details the differential recruitment of cortex in EG as contrasted to IG in light of modern imaging techniques.

In 2006, Elsinger and colleagues published an important paper differentiating IG and EG cortical dynamics during an upper extremity button press task in fMRI (60). Indeed, this group did show that lateral premotor areas were more active during EG response; however, this activity was likely part of a spatial reaction network associated with the monitoring of external stimuli. This network involves the right hemisphere parietal-premotor-frontal eye field regions (93). This monitoring network can be interpreted exquisitely due to the task-selective nature of the regions recruited. The frontal eye fields are critical in processing saccades and act as a visual motor integration respective of higher-level visual input. The spatial processing of object location is strongly associated with right parietal regions, which would necessarily inform premotor areas to prime selection and then execution of accurate motor response. It has been shown that increased task complexity corresponded to an increase in network coherence (60). Because the task was mapping of specific finger movements to external stimuli, the increased activation of this circuit as a result of increased complexity may be interpreted as multisensory integration of proprioceptive, visual, and kinesthetic information.

Cortical recruitment in EG tasks can also be described in the context of movement entrainment or sequence learning. Much attention has been paid to the role of EG in movement training to automaticity (94-97). Using PET, Jenkins et al. (95) was one of the first groups to use neuroimaging techniques to probe motor skill acquisition and the neural correlates that underlie the stages of motor learning (novel stimulus, movement entrainment, and automatic movement). Overall, the cortical representation pattern was characterized as moving from anterior frontal regions to more posterior areas after continued task practice. Specifically, the group denoted that novel motor learning was the only task condition to show activity in the prefrontal cortex. The entrainment phase of motor practice was associated with consistent activity within the SMAs [see also Ref. (98)], while at movement automaticity (maximum performance accuracy), the dominant cortical activity was in the parietal lobe (95). Work involving fMRI has also shown this anterior to posterior shift in cortical recruitment as tasks become well practiced (96) with an overall reduction of volume of cortical regions recruited after automaticity is achieved.

Importantly, the paradigms denoted thus far have only employed upper extremity movements. Much less is known about cortical execution of EG movements in contrast to IG respective of lower extremity movement. Bruce Dobkin's laboratory has published much of the rehabilitation-focused imaging research on the lower extremity. In a series of studies involving the use of lower extremity EG movement, this team denoted reliable recruitment of left SMA, bilateral sensorimotor areas (M1S1), and right parietal lobules $(24,99)$. Other labs have also approached lower limb movement with considerations for rehabilitative outcome. For example, Trinastic et al. (26) attempted to differentiate cortical recruitment in motor cortex during EG plantarflexion as compared to dorsiflexion. Findings showed that although dorsiflexion recruited additional cortical areas as compared to plantarflexion, the tasks commonly recruited medial SMA (26). Kapreli et al. (100) approached lower limb movements relating to motor overlap of the somatosensory network shown in upper extremity movements. In this study, the group reported similar regions of activity between tasks; however, lower limb movements were much less lateralized and tended to recruit both hemispheres during motor activity (100). Laterality differences between upper and lower extremities have been reported during visual monitoring (101) and motor tracking tasks (102) comparing movements of the hand vs. the foot. This increased bilateral response [also reported by Trinastic et al.(26) during dorsiflexion as compared to plantarflexion] in lower extremity tasks as compared to those involving the upper extremity has likely been noted because locomotion requires bilateral coordination to maintain balance $(26,103)$. This differentiation also provides an opportunity for rehabilitation specialists to design interventions that take advantage of the greater cortical recruitment of lower limb movements.

\section{Subcortical Recruitment in EG}

Although there exists regional differentiation of cortical recruitment respective of EG vs. IG movements, the neural system does not function as wholly discrete neural compartments as characterized thus far. Understanding the integration of subcortical and cerebellar structures in light of movement circuits is crucial to properly inform rehabilitation using IG and EG strategies in movement.

As stated earlier, sensory integration during EG task execution is a central component to neural activity in this modality. Without continuous state monitoring (postural, positional, visual, auditory, etc.), coordinating movement with external cues would be impossible. As such, the basal ganglia and thalamic sensory relay centers are critical components to successful EG task execution. To this end, in healthy individuals performing EG tasks, a complex interaction of thalamic (pulvinar, ventroanterior lateral, and ventroposterior lateral), cerebellar, and cortical regions form sensory circuits, which allow for selected task actions to coordinate with cues. 
Taniwaki et al. (104) used fMRI to characterize discrete corticosubcortical circuits associated with IG vs. EG movements in the upper extremity. The group employed a structural equation modeling (SEM) approach with a priori network structures identified to test for path strength between ROIs during EG compared to IG. The group identified discrete ROIs of active structures regardless of movement type before entering the regions into a confirmatory structural equation model. In reference to previous literature and task-based activation in the study (left hand movements), the group identified IG movements with right putamen, globus pallidus, ventrolateral thalamus, dorsomedial thalamus, bilateral ventroposterior lateral thalamus, cerebellum, and SMA. However, the EG movements were associated with right ventral premotor, left ventroposterior lateral thalamus, right dorsomedial thalamus, and bilateral cerebellum. The group tested output path coefficients respective of whether each movement type was associated with CBGT loops or cortico-cerebellar loops. IG involved stronger path links with the CBGT structures listed above. However, EG was associated with stronger cerebellar connectivity to ventral premotor cortex via the thalamus. The cortico-cerebellar connectivity did not involve mediation by the striatum in EG, while IG was strongly associated with putamen activity of the right (contralateral) side. So, although EG tasks appear to be less dependent on the CBGT loops, they rely strongly on cerebellar input (104). Additional work since Taniwaki et al. (104) has largely confirmed this conclusion $(43,73)$.

\section{Cerebellum}

Unsurprisingly, the cortico-cerebellar system is perhaps the most cited neural pathway to be associated primarily with EG movements $(41,43,45-47,60,73,104)$. The importance of cerebellar feedback during EG tasks likely indicates the role of the cerebellum as a modulator of complex motor dynamics and proprioception. The cerebellum acts as a de facto servo system to modulate gross motor action into controlled and coordinated movement. This is also reflected in the cortical networks upstream of cerebellar activity in EG, as the frontal eye fields perform an analogous role in saccades and transitions to smooth pursuit. Additionally, these structures serve in concert with the semicircular canals and the cerebellum (particularly the flocconodular lobe) to regulate postural stability and vestibular state (105).

Imaging studies have expounded upon our understanding of cerebellar function in cued movements that had previously been largely derived from literature related to cerebellar damage (106). Functional MRI of upper extremity movement has indicated discrete lobes of the cerebellum that appear responsible for facilitating movement in response to external cues. For example, 10 healthy right-handed subjects, while fixating on a visual cross, were cued to press a button in response to hearing a sound, causing activations in lobules $\mathrm{V}$ and VI in the right anterior cerebellum (36). With a finger-tapping task similar to the one described above, activations were found in right lobules IV-V and right lobules VIIIA and VIIIB (37). Sauvage et al. (23) compared the neural substrates involved in execution vs. mental imagery of sequential movements (fast and slow) of the left foot in 12 volunteers. Overt movement execution and motor imagery shared a common network: premotor, parietal and cingulate cortices, striatum, and cerebellum (23). Motor imagery recruited the prefrontal cortex, and motor execution recruited the sensorimotor cortex. Slow movements recruited frontopolar and right dorsomedial prefrontal areas bilaterally in execution and motor imagery. Fast movements strongly activated the sensorimotor cerebral cortex. However, the anterior vermis, lobules VI/VII and VIII of the cerebellum were activated in fast movements, in imagery and execution (23). Fast movements are similar to ballistic movements, which have also been implicated in cerebellum imaging studies (107). These findings indicate regional functional specificity potentially exclusive to the execution of EG tasks in the upper and possibly in the lower.

Bostan et al. (108) recently showed that in the cebus monkey, the cerebellum is connected disynaptically with the subthalamic nucleus via the pontine nuclei. While previous work by the group had insinuated structural isolation of the cerebellum from the basal ganglia and STN (68), the findings of this paper clearly show a bidirectional connectivity of these regions in higher order primates. As such, modulation of the STN via cerebellar control is likely implicated in pathophysiology like PD. As described above, the STN exerts powerful effects on the basal ganglia. Given the critical involvement of the cerebellum in EG movements, it is possible that additional cerebellar input accounts for a portion of the behavioral differences of PD patients when comparing IG vs. EG task performance.

Unfortunately, few studies compare EG and IG movements in the lower extremity, which could help delineate the cerebellar components involved with each movement type. Currently, findings indicate EG movements of the lower limb, when employing comparable cues to those used to cue upper limb movements, tend to recruit both overlapping and discrete cortico-cerebellar neural structures $(30,34)$. Just as the cerebellum is involved in IG movements (in addition to the STC circuit), subcortical striatal structures are involved in EG foot movements. Sixteen healthy subjects performed dorsi-plantar flexion of the foot actively (responding to auditory cues at $1.25 \mathrm{~Hz}$ ) and passively. Passive movements activated cortical regions similar (but reduced) to those activated by the active task. Activations during active and passive movement were found not only in the contralateral M1 and $\mathrm{S} 1$ cortices but also in the premotor cortical regions (bilateral rolandic operculum and contralateral SMA) and in subcortical regions (ipsilateral cerebellum and contralateral posterior putamen) (27). Additionally, differential activation has been noted in the cerebellum depending on whether movements are IG or EG, regardless of presence or absence of visual feedback and activation related to proprioceptive input (29). Clearly, this area of inquiry requires additional carefully planned studies to identify cerebellar circuits and auxiliary structures that can be preferentially targeted by EG interventions.

\section{PARKINSON'S DISEASE AND EG}

Parkinson's disease affects both IG and EG movements. However, EG movements may be less impaired in early stages of the disease as compared to IG movements (44). Interestingly, PD is associated with alterations in recruitment of cortico-cerebellar networks despite only mild overt performance differences. For example, Elsinger et al. (48) used the paced finger-tapping task (PFT) (with the right hand) and observed that PD participants 
had decreased accuracy and increased variability on the task compared to controls. Whether the PD participants were on or off dopamine supplementation did not affect task performance. However, decreased activation in the left sensorimotor cortex, cerebellum, and medial premotor system was noted in PD subjects compared to controls (48). In another study, PD participants (tested both on and off anti-parkinsonian medication) and agematched controls participated in an EG sinusoidal force task with visual cues and varying speeds while gripping a squeeze bulb in their right hand. The group reported that off-medication as opposed to on-medication PD participants recruited the bilateral cerebellum and primary motor cortex as compared to onmedication PD participants and controls (40). Cerasa et al. (47) described findings from a right hand, finger-tapping paradigm of IG and EG movement with visual cues in PD patients. Both PD and healthy subjects engaged somewhat similar neural networks in both EG and IG movement, yet the PD group showed greater activity in sensory and associative cortices. For example, in the EG condition, PD subjects showed increased activation of the calcarine cortex bilaterally, potentially indicating an increased reliance on visual input for task performance. In the IG condition, the cerebello-thalamic pathway was shown to be involved to a greater degree in PD subjects, possibly denoting a compensatory modality shift to EG mapping, which is perhaps more robust to failure in PD than neurotypical IG pathways (47).

With respect to lower extremity function, recent findings have been mixed regarding cerebellar changes in PD. For example, Schwingenschuh and colleagues, using an EG ankle dorsiflexion task, found that people with PD activated lobules I-V in the ipsilateral cerebellum during EG movement, and similar cerebellar activations were found for healthy controls. After oral administration of levodopa, the PD participants showed increased activity in subcortical structures (contralateral putamen and thalamus), compared to control participants who showed no alteration of function. These findings suggest that the cortico-subcortical motor circuit in PD is sensitive to exogenous dopamine administration (25). Externally cued motor imagery has also been employed during fMRI to probe changes in corticocerebellar structures in gait. Cremers et al. (109) reported that people with PD compared to healthy controls had decreased activity in cerebellar vermis and SMA. Importantly, individuals with PD who exhibited greater gait disturbance were less likely to recruit cerebellar and cortical regions characterized by the healthy control group during gait visualization (109). This finding is in contrast with results of Spraker et al. who noted increased recruitment of cerebellar structures and pathways with disease progression (110). Interestingly, what might account for the varied results between studies is the relative difficulty with which studies using fMRI can quantify modulation of cortical structures by the basal ganglia. Recently, Cagnan et al. (111) demonstrated using LFPs with people with $\mathrm{PD}$ that phasic synchronization of basal ganglia structures is more associated with tremor and motor dysfunction in PD. Interestingly, when on dopaminergic treatment, the phase locking in beta waveforms in STN and globus pallidus abated to a more dynamic oscillation and, importantly, the individuals with PD exhibited improved motor function. Possibly, were LFPs in STN to be acquired in concert with EEG, alteration of cerebellar and cortical activity may indeed reflect oscillatory activity in the beta frequency range. In turn, combining the three techniques, while methodologically challenging, may help account for the varying reports of cortical involvement using fMRI.

At present, due to the dearth of research involving lower limb movement and imaging, drawing any conclusions about the effect of PD on neural circuits respective of EG movements in the lower extremity is challenging. Table 1 lists a summary of the relevant imaging studies in the context of IG vs. EG movement in healthy controls and individuals with $\mathrm{PD}$, which were considered in the text above. Clearly, there are many questions to be answered, making this investigation important for consideration for motor and rehabilitation scientists.

\section{REHABILITATION PROGRAMS FOCUSED ON RHYTHMIC MOVEMENT}

Until this point, this review has attempted to elucidate the neural mechanisms that are involved with IG and EG movements respective of the hand and foot respective of both healthy individuals and individuals with PD. We now turn to modern rehabilitative programs that may select for a movement modality or their interaction. These programs selectively engage and optimize movement using internal or external cues, or in many cases, both.

Therapy programs that include external guidance through consistent rhythmic auditory stimulation (RAS) (e.g., a metronome or music) can facilitate movements and are recommended for people with PD. RAS has been used to improve gait in those with PD via external sensory cues consisting of metronome beats. Studies have shown the positive effects of RAS on FOG and gait parameters (112). Although other sensory cues such as visual and proprioceptive cues have been examined, auditory cues appear to be most effective in improving gait in PD (113). Coupling gait to rhythmic auditory cues may rely on a neural network engaged in both perceptual and motor timing in individuals with PD (114). In fact, some individuals with PD may have an impaired perception of beat timing. Leow et al. (115) examined the impact of beat salience in effectively improving gait cadence and other parameters by comparing "high groove" (i.e., music with a strong underlying beat) to "low groove" music. Individuals with poorer perception of beat timing were helped by high groove music because of the salience of the beat. Such musical support might help facilitate gait in those with PD. This finding is highly relevant to dance- or music-based rehabilitation because poor or good beat perception affects gait performance when synchronized to music (115). Leow et al. also showed that more familiar music elicited less variable strides and faster stride velocity and better synchronization with the music (116). Salience of a beat (as mentioned above) and familiarity with music are therefore considerations for rehabilitative purposes.

Indeed, music therapies may have some utility in ameliorating some function in individuals with PD. Recently, Bella et al. trained PD participants on musically cued gait therapy, consisting of synchronizing movement to familiar folk music without lyrics (a bell cued participants' movement). Findings included not only increased gait speed and stride length but also strong gains in motor synchronization (tapping) and perceptual awareness on just noticeably different tasks (117). Findings from stroke 
literature and the application of music-supported therapy (MST) might also shed light on possible beneficial effects of rhythmic movement with auditory support for people with PD. MST uses musical instrument playing to treat paresis of the upper limb and adheres to four principles: massive repetition, audio-motor coupling, shaping, and emotion-motivation effects. After 4 weeks of MST in combination with usual care, chronic stroke participants assigned to MST showed improvements on the Wolf motor function test in comparison to a control group (118). Additionally, a case study revealed audio-motor coupling when a patient was exposed to a passive listening task with unfamiliar and trained melodies. Before MST, only the auditory cortices were activated; after MST, motor regions were also activated (119). Given that participants actually play an instrument, MST is an intriguing form of musical therapy that can exploit benefits of both EG and IG strategies, and their accompanying neural circuitry.

A meta-analysis recently demonstrated that music-based therapy, including dance, positively affects PD gait and gait-related activities (120). Recently, dance has indeed gained attention as a music-based therapy that may be able to effectively address impairments related to PD. An understudied aspect of dance interventions is the interplay of external vs. internal guidance across multiple sensory modalities. Proprioceptive and kinesthetic inputs based on tactile cues are crucial for motor adaptation and dance performance. Visual cues no doubt play a role in postural control, navigation, and emotional understanding, as well as having a curious positive effect on FOG. However, auditory cues (e.g., percussion or other musical rhythms) play a strong role in guidance of movement and can be EG (e.g., bass percussion) or IG [e.g., fermata pause (notes held longer than music's tempo)] or even delivered as disruptive asynchrony (e.g., syncopation). We believe rehabilitation regimens like dance and other rhythmic training likely provide a synergistic multisensory adjuvant to motor skills training in both aging and disease models. However, in consideration of the discussion of the neural pathways associated with IG and EG motor training strategies, answering the question why dance may be effective is helpful. At this point, it is unclear to what extent external musical auditory or visual (and tactile, in the case of any sort of partnered/contact dance) cues play to elicit therapeutic effects vs. the improvements gained by increased attention and cognitive engagement used to plan and enact movement. Studies are needed to answer these questions when considering the research that has accumulated supporting beneficial effects of rehabilitative methods involving rhythmic training.

\section{Dance Therapy}

In the last 10 years, a series of studies have investigated the effects of adapted Argentine tango dance (adapted tango) for individuals with PD. Participants experienced significant gains in mobility, balance, and QOL (121-124). These improvements were maintained 1 month later, (123) and up to 3 months later (125, 126). After participating in 1 year of tango classes offered in the community, participants with PD also demonstrated decreased disease severity (127). Recently, a study demonstrated a 12 -week adapted tango program, which was disseminated to several novice instructors and offered in the community, improved spatial cognition, as well as disease severity in participants with mild-moderate
PD (126). Other forms of dance have been investigated for efficacy for those with PD. A study that investigated the feasibility of Irish set dancing, in comparison to standard physiotherapy, found the dancing safe and feasible. Furthermore, participants tended to improve more in gait, balance, and FOG after dancing, than after the standard care (128). Dance may have an immediate effect on mobility in those with PD as improvements have been found in as little as 2 weeks of tango (129) and contact improvisation training (130). The very popular "Dance for PD" method has been investigated for its efficacy, and it was found to improve the motor subscale of the UPDRS after 16 sessions ( $20 \mathrm{~h}$ of treatment) in an uncontrolled study (131).

Because several studies have been conducted on the efficacy of tango, it will be examined and considered for its qualities, to serve as an exemplar with qualities that can relatively easily be identified within the IG/EG dichotomy. Argentine tango has steps, patterns, music, and importantly, partnering that may address specific impairments associated with PD. Partner dancing is a sophisticated, yet accessible system of tactile communication that conveys motor intentions and goals between a "leader" (planner of movement) and "follower" (externally cued mover). An "embrace" or "frame" between the leader and follower is the position maintained by the arms throughout all steps in adapted tango. In adapted tango classes $(121,123,125)$, participants consistently both led and followed all dance steps with healthy partners, and therefore alternated between two motor training approaches (a) leading, consisting of internally guiding movement plans and (b) following, consisting of responding to external guidance. Thus, qualities of effective rehabilitative programs are found in both leading and following within the context of adapted tango. While in the role of leader, participants practice self-directed, internally generated movements; while, in the role of follower, participants practice responding to external cues from the partner. There are key differences between leading and following that may address specific needs and result in distinct training gains in mobility, because as we have outlined above the neural circuitry that drives leading and following movement likely differs.

Individuals who perform the leading role in dance are thought to adopt a world-centric reference frame. To lead a dance successfully, these individuals need to multi-task by focusing on environment, follower, music, and both current and future motor plans. Leading, which should be using IG cognitive and motor skill, is thought to involve employing a "movement strategy" that demands increased focus on movement plans and mentally rehearsing and/or preparing for movement. Leaders in partnered dances must determine precise spatiotemporal movement parameters of a dance sequence, e.g., amplitude, direction, timing, and rotation. As such, leading may pose a challenge for individuals with PD, given that many have impaired executive control, specifically in cognitive processes involved in planning and executing complex, goal-directed behavior $(11,132)$. Importantly, the individual who follows in adapted Argentine tango is not required to plan precise spatiotemporal parameters of movement (e.g., direction, length of step, timing, and amount of rotation). From moment to moment, the follower receives movement guidance regarding the afore-mentioned parameters from the leader via tactile cues. Because followers are not devoting attentional resources to planning movement, potentially they can attend more 
to their postural control, which becomes more and more necessary as a person ages or contends with a neurodegenerative movement disorder.

Although the adapted tango dichotomy of leading and following roles provides a convenient analog to the "ideal" EG and IG motor training vehicle, it must be admitted that underlying strongly rhythmic movements that characterize dance forms continuously employ both EG and IG strategies. Whether these rhythms are internally created or manifested from external guidance (from music and tactile cues of a leader), dance movements obey their inherent timing. As such, rhythmic cues may be very responsible for any gains seen in $\mathrm{PD}$ rehabilitation as a result of dance participation. However, in practice, it can be challenging to both train a person with PD (or even a "healthy" individual) in complex shapes of a dance form and also teach them the sophisticated rhythms that make up most dances. As such, the consideration of shape vs. timing must be acknowledged.

The "shape" of a movement sequence is the simple biomechanics of the steps, irrespective of speed or timing. Rhythm usually refers to a repetitive pulse that is repeated in cycles through a musical or movement form. Even IG movement, which does not appear to "obey" a particular repeated rhythm has an intrinsic timing, and occupies a temporal space [see Ref. (75)]. In a dance class for people with motor challenges, there are a number of stages through which a dancer may go in order to achieve dance mastery, which includes a mastery of coordinating movement to music. This movement entrainment may or may not be the same as reports from Wu et al. (96) investigating finger movement training to automaticity, as coordinated rhythmic movements involve a much more complex interplay of IG and EG timing. During rhythmic training, in the first/novice stage, the individual begins to understand a dance pattern, and puts their body through novel motions that will occupy some sort of temporal space, but may not align precisely with a dictated rhythm/timing given by an instructor. With practice the dancer enters a second stage, in which he/she has the motor control to coordinate his bodily timing to the musical timing. As the steps become more complex, there is vacillation between the first and second stages. But whether or not the dancer (a) benefits from precisely moving to the beat of the music, or the dance rhythm (b) from listening to the music, and/or - thinking - they are moving precisely to the beat and obeying a dance rhythm, or (c) benefits mostly from concentrating on the shape of the movement, while creating their own internal rhythmic timing, is unclear.

The role of the instructor is extremely important with respect to properly implementing adapted rhythmic training programs, as the trained instructor becomes the model by which the individual gages performance. During initial instruction, the student models performance externally by visual approximation of his or her own movement to that idealized by the instructor. As the student progresses and achieves additional kinesthetic feedback and motor flow during the rhythmic movement, motor adaptation translates from externally derived imitation to IG motor flow. However, despite this transition, the role of the instructor to provide the movement template is central to successful training. In these regards, the student's interpersonal relationship with their instructor has great import on their training trajectory; however, this relationship necessarily introduces variability due to social interaction between student and teacher. Interestingly, recent work has approached the interpersonal dynamics involving adapted tango. A research group at Emory University and Georgia Tech has been investigating the ability of robots to act as leaders and followers in a simple tango step pattern. The robots are able to maintain a stable distance from their human partner, characteristics of a human counterpart. While experiments using these robots are ongoing, a recent report demonstrated that expert dancers have indicated reasonable ecological validity of the leading and following performance of the robots (133). This line of work offers unique insights as to the effects of interpersonal dynamics on rehabilitative outcome using dance therapy. Furthermore, these investigations could serve as an interesting platform upon which to test ideas about IG and EG movement schemas.

\section{RHYTHMIC MOVEMENT IN REHABILITATION OF INTERNALLY AND EXTERNALLY GUIDED MOVEMENT}

At this time, few studies offer evidence of neural changes as a result of focused training in people with $\mathrm{PD}$ or healthy controls. A study utilizing PET showed improved vocal intensity after training in the Lee Silverman voice training (LSVT) LOUD program for speech improvement. These motor improvements were correlated with modification in motor, auditory, and prefrontal areas, but there was no effect on the basal ganglia (134). However, in healthy participants lying supine, increased activity in the putamen was noted using PET when tango movements were performed with a single limb to a metered beat (135). In a related finding, after a week of tango lessons, healthy adults exhibited increased activity of supplementary motor (SMA) and premotor cortices during imagined tango-style walking. In participants who had completed a week of locomotor attention training involving physical and mental practice, activation was examined during an overt foot motor task consisting of ankle dorsiflexion. Posttraining the foot task showed reorganization of sensorimotor areas, in keeping with other studies on lower limb motor learning, suggesting that functional connectivity of the sensorimotor network may be modulated by focusing attention on the movements involved in ambulation $(136,137)$. Dobkin et al. (24) assessed how ankle dorsiflexion could be utilized as an fMRI paradigm to measure the efficacy of a rehabilitative strategy - body weight-supported treadmill training - for hemiparetic subjects. During voluntary ankle movement, the subjects completed two sets of five isolated movements of $10^{\circ}$. The study observed reorganization in the brain with training; specifically, decreased activity in the ipsilateral primary sensorimotor cortex (S1M1) as therapy gains increased and by 2-6 weeks of training, three of the four subjects saw increased activity in the contralateral S1M1 (24). More studies are clearly needed to examine neural changes in combination with observed clinical motor and cognitive changes, particularly with respect to particular motor training strategies.

\section{LIMITATIONS}

As stated earlier, there is a paucity of research investigating the neural correlates of lower limb movements in aging and disease. 
As such, much of the research concerned with initiation of movement from an IG vs. EG perspective is derived from work in the upper extremity. While we have noted overlap of cortical, subcortical, and cerebellar structures when comparing IG against EG movements of the hand and foot, considerable variation has also been reported particularly regarding laterality of movement. While this variation might, in part, limit interpretation in the current review, its presence provides a direct opportunity for inquiry in both basic science and applied rehabilitation investigations. In addition, a challenge that Dobkin et al. have described in imaging-related literature in rehabilitation is the problem of describing neural activity using BOLD imaging respective of time of data acquisition - both post-onset of pathology and progression through the rehabilitation regimen (24). The group has provided evidence that neural activity during early training tends to be larger in volume. However, with increasing exposure, despite similar task performance, neural activity appears to be consolidated to smaller cortical volumes. This presents a challenge in the review of rehabilitation literature as simple static statistical threshold comparisons of activity volumes across studies conflate the neurological variability of the substrates under consideration due to both age and the rehabilitation regimen. Again, due to the low number of rehabilitation studies comparing IG vs. EG in the imaging literature, we lack the statistical tools to describe this variability properly in the current review. Perhaps most importantly, in the current review, we have not discussed the critical aspect of dosing of rehabilitative regimens engaging in EG and IG movement strategies. The identification of an optimized amount of treatment has been overlooked in rehabilitation research. This may have been of necessity given the field has been engaged in identifying specific regimens for efficacy. However, given recent success in identifying programs, it is appropriate to begin to ask the question, "how much?" and to probe for differences between IG and EG motor training with respect to dose. Furthermore, this review has only very briefly outlined the investigation into musicbased and dance-based therapies within the PD population and has likely not thoroughly covered the rhythmic and cognitively driven (IG) aspects of other forms of exercise (e.g., spinning, Tai Chi, walking, swimming, and boxing), which deserve attention.

\section{CONCLUSION}

Underlying mechanistic commonalities may exist among therapies that effectively target symptoms of individuals with PD (138). As a jumping off point, one can consider the effects of levodopa and deep brain stimulation, the current standard of care treatment

\section{REFERENCES}

1. Amano S, Nocera JR, Vallabhajosula S, Juncos JL, Gregor RJ, Waddell DE, et al. The effect of Tai Chi exercise on gait initiation and gait performance in persons with Parkinson's disease. [Multicenter Study Randomized Controlled Trial Research Support, N.I.H., Extramural]. Parkinsonism Relat Disord (2013) 19(11):955-60. doi:10.1016/j.parkreldis.2013.06.007

2. Earhart GM. Dance as therapy for individuals with Parkinson disease. Eur J Phys Rehabil Med (2009) 45(2):231-8.

3. Hackney ME, Earhart GM. Tai Chi improves balance and mobility in people with Parkinson disease. Gait Posture (2008) 28(3):456-60. doi:10.1016/j. gaitpost.2008.02.005 for today's population with PD. As with the case of deep brain stimulation, suppression of abnormal downstream network activity produced by the malfunctioning basal ganglia may result from stimulating the subthalamic nucleus (139). Rehabilitation may also create changes downstream of basal ganglia structures. If the mechanism of improvement resulting from IG motor training is similar, there may be a reduction in abnormal neural activity along the STC circuit, which likely mediates IG motor tasks and includes the putamen, ventral anterior thalamus, rostral SMA, and primary motor cortex. An alternative possibility could be increased activity in the basal ganglia, which have been demonstrated to be hypoactive in drug-naïe individuals in early stages of PD (140). Moreover, when examining twins discordant for PD performing right hand, finger sequencing tasks for task specific influences on the STC and CTC pathways before and after levodopa administration, it was noted that levodopa corrected hypoactivation in the contralateral STC, but over-corrected activation in the ipsilateral STC and bilateral CTC pathways; therefore, standard PD pharmacology affects compensatory changes (51) and effective IG or EG motor training as well. Nevertheless, currently, insufficient evidence exists to determine the mechanisms by which IG and EG motor training are efficacious, and future work is necessary to do so. Furthermore, to understand the mechanisms underlying impairments and training effects in whole-body balance and mobility tasks, lower limb neural activity must be investigated first within the context of IG and EG tasks in individuals with and without PD. Knowledge about neural changes that may occur after repeated and targeted training with IG or EG tasks will allow us to develop better rehabilitation training strategies for those with PD and supplement pharmacological and surgical developments.

\section{AUTHOR CONTRIBUTIONS}

$\mathrm{MH}$ and $\mathrm{KM}$ drafted the manuscript, performed literature review, and edited the final manuscript for submission. HL and JB contributed literature search and review and tabular organization. BC performed final review and critical appraisal of the manuscript.

\section{FUNDING}

This work is supported by the US Department of Veterans Affairs' Rehabilitation Research and Development grants: \#0870-01A1$\mathrm{MH}$ and E-0956W-KM. The views and opinions of authors expressed herein do not necessarily state or reflect those of the United States Government.

4. Kadivar Z, Corcos DM, Foto J, Hondzinski JM. Effect of step training and rhythmic auditory stimulation on functional performance in Parkinson patients. Neurorehabil Neural Repair (2011) 25(7):626-35. doi:10.1177/ 1545968311401627

5. Morris ME, Iansek R, Kirkwood B. A randomized controlled trial of movement strategies compared with exercise for people with Parkinson's disease. Mov Disord (2009) 24(1):64-71. doi:10.1002/mds.22295

6. Ridgel AL, Vitek JL, Alberts JL. Forced, not voluntary, exercise improves motor function in Parkinson's disease patients. Neurorehabil Neural Repair (2009) 23(6):600-8. doi:10.1177/1545968308328726

7. Tsai ST, Lin SH, Chou YC, Pan YH, Hung HY, Li CW, et al. Prognostic factors of subthalamic stimulation in Parkinson's disease: a comparative 
study between short- and long-term effects. Stereotact Funct Neurosurg (2009) 87(4):241-8. doi:10.1159/000225977

8. Alexander GE, DeLong MR, Strick PL. Parallel organization of functionally segregated circuits linking basal ganglia and cortex. Annu Rev Neurosci (1986) 9:357-81. doi:10.1146/annurev.ne.09.030186.002041

9. Jueptner M, Weiller C. A review of differences between basal ganglia and cerebellar control of movements as revealed by functional imaging studies. Brain (1998) 121(Pt 8):1437-49. doi:10.1093/brain/121.8.1437

10. Eckert T, Peschel T, Heinze HJ, Rotte M. Increased pre-SMA activation in early PD patients during simple self-initiated hand movements. J Neurol (2006) 253(2):199-207. doi:10.1007/s00415-005-0956-Z

11. Low KA, Miller J, Vierck E. Response slowing in Parkinson's disease: a psychophysiological analysis of premotor and motor processes. Brain (2002) 125(Pt 9):1980-94. doi:10.1093/brain/awf206

12. Wu T, Wang L, Hallett M, Chen Y, Li K, Chan P. Effective connectivity of brain networks during self-initiated movement in Parkinson's disease. Neuroimage (2011) 55(1):204-15. doi:10.1016/j.neuroimage.2010.11.074

13. Rochester L, Jones D, Hetherington V, Nieuwboer A, Willems AM, Kwakkel G, et al. Gait and gait-related activities and fatigue in Parkinson's disease: what is the relationship? Disabil Rehabil (2006) 28(22):1365-71. doi:10.1080/ 09638280600638034

14. Nieuwboer A, Rochester L, Muncks L, Swinnen SP. Motor learning in Parkinson's disease: limitations and potential for rehabilitation. Parkinsonism Relat Disord (2009) 15(Suppl 3):S53-8. doi:10.1016/S1353-8020(09)70781-3

15. Dibble LE, Nicholson DE, Shultz B, MacWilliams BA, Marcus RL, Moncur C. Sensory cueing effects on maximal speed gait initiation in persons with Parkinson's disease and healthy elders. Gait Posture (2004) 19(3):215-25. doi: 10.1016/S0966-6362(03)00065-1

16. Jiang Y, Norman KE. Effects of visual and auditory cues on gait initiation in people with Parkinson's disease. Clin Rehabil (2006) 20(1):36-45. doi:10.1191/ 0269215506cr925oa

17. Ballanger B, Thobois S, Baraduc P, Turner RS, Broussolle E, Desmurget M. "Paradoxical kinesis" is not a hallmark of Parkinson's disease but a general property of the motor system. Mov Disord (2006) 21(9):1490-5. doi:10.1002/ mds.20987

18. Howe TE, Lovgreen B, Cody FW, Ashton VJ, Oldham JA. Auditory cues can modify the gait of persons with early-stage Parkinson's disease: a method for enhancing parkinsonian walking performance? Clin Rehabil (2003) 17(4):363-7. doi:10.1191/0269215503cr621oa

19. Plotnik M, Hausdorff JM. The role of gait rhythmicity and bilateral coordination of stepping in the pathophysiology of freezing of gait in Parkinson's disease. Mov Disord (2008) 23(Suppl 2):S444-50. doi:10.1002/mds.21984

20. McIntosh GC, Brown SH, Rice RR, Thaut MH. Rhythmic auditory-motor facilitation of gait patterns in patients with Parkinson's disease. J Neurol Neurosurg Psychiatry (1997) 62(1):22-6. doi:10.1136/jnnp.62.1.22

21. Nieuwboer A, Kwakkel G, Rochester L, Jones D, van Wegen E, Willems AM, et al. Cueing training in the home improves gait-related mobility in Parkinson's disease: the RESCUE trial. J Neurol Neurosurg Psychiatry (2007) 78(2):134-40. doi:10.1136/jnnp.200X.097923

22. Thaut MH, McIntosh GC, Rice RR, Miller RA, Rathbun J, Brault JM. Rhythmic auditory stimulation in gait training for Parkinson's disease patients. Mov Disord (1996) 11(2):193-200. doi:10.1002/mds.870110213

23. Sauvage C, Jissendi P, Seignan S, Manto M, Habas C. Brain areas involved in the control of speed during a motor sequence of the foot: real movement versus mental imagery. J Neuroradiol (2013) 40(4):267-80. doi:10.1016/j.neurad. 2012.10.001

24. Dobkin BH, Firestine A, West M, Saremi K, Woods R. Ankle dorsiflexion as an fMRI paradigm to assay motor control for walking during rehabilitation. Neuroimage (2004) 23(1):370-81. doi:10.1016/j.neuroimage.2004.06.008

25. Schwingenschuh P, Katschnig P, Jehna M, Koegl-Wallner M, Seiler S, Wenzel $\mathrm{K}$, et al. Levodopa changes brain motor network function during ankle movements in Parkinson's disease. J Neural Transm (2013) 120(3):423-33. doi:10.1007/s00702-012-0896-6

26. Trinastic JP, Kautz SA, McGregor K, Gregory C, Bowden M, Benjamin MB, et al. An fMRI study of the differences in brain activity during active ankle dorsiflexion and plantarflexion. Brain Imaging Behav (2010) 4(2):121-31. doi: 10.1007/s11682-010-9091-2

27. Ciccarelli O, Toosy AT, Marsden JF, Wheeler-Kingshott CM, Sahyoun C, Matthews PM, et al. Identifying brain regions for integrative sensorimotor processing with ankle movements. Exp Brain Res (2005) 166(1):31-42. doi:10. 1007/s00221-005-2335-5

28. Wai YY, Wang JJ, Weng YH, Lin WY, Ma HK, Ng SH, et al. Cortical involvement in a gait-related imagery task: comparison between Parkinson's disease and normal aging. Parkinsonism Relat Disord (2012) 18(5):537-42. doi:10. 1016/j.parkreldis.2012.02.004

29. Christensen MS, Lundbye-Jensen J, Petersen N, Geertsen SS, Paulson OB, Nielsen JB. Watching your foot move - an fMRI study of visuomotor interactions during foot movement. Cereb Cortex (2007) 17(8):1906-17. doi:10.1093/ cercor/bhl101

30. Volz LJ, Eickhoff SB, Pool EM, Fink GR, Grefkes C. Differential modulation of motor network connectivity during movements of the upper and lower limbs. Neuroimage (2015) 119:44-53. doi:10.1016/j.neuroimage.2015.05.101

31. Cunningham DA, Machado A, Yue GH, Carey JR, Plow EB. Functional somatotopy revealed across multiple cortical regions using a model of complex motor task. CBrain Res (2013) 1531:25-36. doi:10.1016/j.brainres. 2013.07.050

32. Kuper M, Thurling M, Stefanescu R, Maderwald S, Roths J, Elles HG, et al. Evidence for a motor somatotopy in the cerebellar dentate nucleus - an FMRI study in humans. [Research Support, Non-U.S. Gov't]. Hum Brain Mapp (2012) 33(11):2741-9. doi:10.1002/hbm.21400

33. Van Impe A, Coxon JP, Goble DJ, Wenderoth N, Swinnen SP. Ipsilateral coordination at preferred rate: effects of age, body side and task complexity. Neuroimage (2009) 47(4):1854-62. doi:10.1016/j.neuroimage.2009.06.027

34. Schlerf JE, Verstynen TD, Ivry RB, Spencer RM. Evidence of a novel somatopic map in the human neocerebellum during complex actions. J Neurophysiol (2010) 103(6):3330-6. doi:10.1152/jn.01117.2009

35. Wasson P, Prodoehl J, Coombes SA, Corcos DM, Vaillancourt DE. Predicting grip force amplitude involves circuits in the anterior basal ganglia. Neuroimage (2010) 49(4):3230-8. doi:10.1016/j.neuroimage.2009.11.047

36. Salmi J, Pallesen KJ, Neuvonen T, Brattico E, Korvenoja A, Salonen O, et al. Cognitive and motor loops of the human cerebro-cerebellar system. [Research Support, N.I.H., Extramural Research Support, Non-U.S. Gov't]. J Cogn Neurosci (2010) 22(11):2663-76. doi:10.1162/jocn.2009.21382

37. Stoodley CJ, Valera EM, Schmahmann JD. Functional topography of the cerebellum for motor and cognitive tasks: an fMRI study. Neuroimage (2012) 59(2):1560-70. doi:10.1016/j.neuroimage.2011.08.065

38. Wiestler T, McGonigle DJ, Diedrichsen J. Integration of sensory and motor representations of single fingers in the human cerebellum. J Neurophysiol (2011) 105(6):3042-53. doi:10.1152/jn.00106.2011

39. Vaillancourt DE, Yu H, Mayka MA, Corcos DM. Role of the basal ganglia and frontal cortex in selecting and producing internally guided force pulses. Neuroimage (2007) 36(3):793-803. doi:10.1016/j.neuroimage.2007.03.002

40. Palmer SJ, Ng B, Abugharbieh R, Eigenraam L, McKeown MJ. Motor reserve and novel area recruitment: amplitude and spatial characteristics of compensation in Parkinson's disease. Eur J Neurosci (2009) 29(11):2187-96. doi:10. 1111/j.1460-9568.2009.06753.x

41. Gowen E, Miall RC. Differentiation between external and internal cuing: an fMRI study comparing tracing with drawing. Neuroimage (2007) 36(2):396-410. doi:10.1016/j.neuroimage.2007.03.005

42. Vercruysse S, Spildooren J, Heremans E, Wenderoth N, Swinnen SP, Vandenberghe $\mathrm{W}$, et al. The neural correlates of upper limb motor blocks in Parkinson's disease and their relation to freezing of gait. Cereb Cortex (2014) 24(12):3154-66. doi:10.1093/cercor/bht170

43. Francois-Brosseau FE, Martinu K, Strafella AP, Petrides M, Simard F, Monchi O. Basal ganglia and frontal involvement in self-generated and externallytriggered finger movements in the dominant and non-dominant hand [Research Support, Non-U.S. Gov't]. Eur J Neurosci (2009) 29(6):1277-86. doi:10.1111/j.1460-9568.2009.06671.x

44. Jahanshahi M, Jenkins IH, Brown RG, Marsden CD, Passingham RE, Brooks DJ. Self-initiated versus externally triggered movements. I. An investigation using measurement of regional cerebral blood flow with PET and movementrelated potentials in normal and Parkinson's disease subjects. Brain (1995) 118(Pt 4):913-33. doi:10.1093/brain/118.4.913

45. Debaere F, Wenderoth N, Sunaert S, Van Hecke P, Swinnen SP. Internal vs external generation of movements: differential neural pathways involved in bimanual coordination performed in the presence or absence of augmented visual feedback. [Clinical Trial Research Support, Non-U.S. Gov't]. Neuroimage (2003) 19(3):764-76. doi:10.1016/S1053-8119(03)00148-4 
46. Sen S, Kawaguchi A, Truong Y, Lewis MM, Huang X. Dynamic changes in cerebello-thalamo-cortical motor circuitry during progression of Parkinson's disease. Neuroscience (2010) 166(2):712-9. doi:10.1016/j.neuroscience.2009. 12.036

47. Cerasa A, Hagberg GE, Peppe A, Bianciardi M, Gioia MC, Costa A, et al. Functional changes in the activity of cerebellum and frontostriatal regions during externally and internally timed movement in Parkinson's disease. Brain Res Bull (2006) 71(1-3):259-69. doi:10.1016/j.brainresbull.2006.09.014

48. Elsinger CL, Rao SM, Zimbelman JL, Reynolds NC, Blindauer KA, Hoffmann RG. Neural basis for impaired time reproduction in Parkinson's disease: an fMRI study. J Int Neuropsychol Soc (2003) 9(7):1088-98. doi:10.1017/ S1355617703970123

49. Vaillancourt DE, Thulborn KR, Corcos DM. Neural basis for the processes that underlie visually guided and internally guided force control in humans. J Neurophysiol (2003) 90(5):3330-40. doi:10.1152/jn.00394.2003

50. Hoffstaedter F, Grefkes C, Zilles K, Eickhoff SB. The "what" and "when" of selfinitiated movements. Cereb Cortex (2013) 23(3):520-30. doi:10.1093/cercor/ bhr391

51. Lewis MM, Slagle CG, Smith AB, Truong Y, Bai P, McKeown MJ, et al. Task specific influences of Parkinson's disease on the striato-thalamocortical and cerebello-thalamo-cortical motor circuitries. Neuroscience (2007) 147(1):224-35. doi:10.1016/j.neuroscience.2007.04.006

52. Ogawa K, Inui T, Sugio T. Separating brain regions involved in internally guided and visual feedback control of moving effectors: an event-related fMRI study. Neuroimage (2006) 32(4):1760-70. doi:10.1016/j.neuroimage. 2006.05.012

53. Keele SW, Pokorny RA, Corcos DM, Ivry R. Do perception and motor production share common timing mechanisms: a correctional analysis. Acta Psychol (Amst) (1985) 60(2-3):173-91. doi:10.1016/0001-6918(85)90054-X

54. Lee MY, Chang PH, Kwon YH, Jang SH. Differences of the frontal activation patterns by finger and toe movements: a functional MRI study. Neurosci Lett (2013) 533:7-10. doi:10.1016/j.neulet.2012.11.041

55. Sahyoun C, Floyer-Lea A, Johansen-Berg H, Matthews PM. Towards an understanding of gait control: brain activation during the anticipation, preparation and execution of foot movements. Neuroimage (2004) 21(2):568-75. doi:10. 1016/j.neuroimage.2003.09.065

56. Halsband U, Matsuzaka Y, Tanji J. Neuronal activity in the primate supplementary, pre-supplementary and premotor cortex during externally and internally instructed sequential movements. Neurosci Res (1994) 20(2):149-55. doi:10.1016/0168-0102(94)90032-9

57. Mushiake H, Inase M, Tanji J. Neuronal activity in the primate premotor, supplementary, and precentral motor cortex during visually guided and internally determined sequential movements. J Neurophysiol (1991) 66(3):705-18.

58. Dum RP, Strick PL. Motor areas in the frontal lobe of the primate. Physiol Behav (2002) 77(4-5):677-82. doi:10.1016/S0031-9384(02)00929-0

59. Picard N, Strick PL. Motor areas of the medial wall: a review of their location and functional activation. Cereb Cortex (1996) 6(3):342-53. doi:10.1093/ cercor/6.3.342

60. Elsinger CL, Harrington DL, Rao SM. From preparation to online control: reappraisal of neural circuitry mediating internally generated and externally guided actions. Neuroimage (2006) 31(3):1177-87. doi:10.1016/j.neuroimage. 2006.01 .041

61. Nachev P, Wydell H, O'Neill K, Husain M, Kennard C. The role of the pre-supplementary motor area in the control of action. Neuroimage (2007) 36(Suppl 2):T155-63. doi:10.1016/j.neuroimage.2007.03.034

62. Wiener M, Turkeltaub P, Coslett HB. The image of time: a voxel-wise metaanalysis. Neuroimage (2010) 49(2):1728-40. doi:10.1016/j.neuroimage.2009. 09.064

63. Grodzinsky Y, Friederici AD. Neuroimaging of syntax and syntactic processing. Curr Opin Neurobiol (2006) 16(2):240-6. doi:10.1016/j.conb.2006. 03.007

64. Wierenga CE, Maher LM, Moore AB, White KD, McGregor K, Soltysik DA, et al. Neural substrates of syntactic mapping treatment: an fMRI study of two cases. J Int Neuropsychol Soc (2006) 12(1):132-46. doi:10.1017/ S135561770606019X

65. Clerget E, Badets A, Duque J, Olivier E. Role of Broca's area in motor sequence programming: a cTBS study. Neuroreport (2011) 22(18):965-9. doi:10.1097/ WNR.0b013e32834d87cd
66. Inase M, Tokuno H, Nambu A, Akazawa T, Takada M. Corticostriatal and corticosubthalamic input zones from the presupplementary motor area in the macaque monkey: comparison with the input zones from the supplementary motor area. Brain Res (1999) 833(2):191-201. doi:10.1016/S0006-8993(99) 01531-0 Erratum in: Brain Res 2000 Apr 7;861(1):190.

67. Menon V, Glover GH, Pfefferbaum A. Differential activation of dorsal basal ganglia during externally and self paced sequences of arm movements. Neuroreport (1998) 9(7):1567-73. doi:10.1097/00001756-199805110-00058

68. Middleton FA, Strick PL. Basal ganglia and cerebellar loops: motor and cognitive circuits. Brain Res Brain Res Rev (2000) 31(2-3):236-50. doi:10.1016/ S0165-0173(99)00040-5

69. Marchand WR, Lee JN, Suchy Y, Garn C, Johnson S, Wood N, et al. Age-related changes of the functional architecture of the cortico-basal ganglia circuitry during motor task execution. Neuroimage (2011) 55(1):194-203. doi:10.1016/ j.neuroimage.2010.12.030

70. Bartolo R, Prado L, Merchant H. Information processing in the primate basal ganglia during sensory-guided and internally driven rhythmic tapping. $J$ Neurosci (2014) 34(11):3910-23. doi:10.1523/JNEUROSCI.2679-13.2014

71. Teki S. Beta drives brain beats. Front Syst Neurosci (2014) 8:155. doi:10.3389/ fnsys. 2014.00155

72. Bartolo R, Merchant H. beta oscillations are linked to the initiation of sensorycued movement sequences and the internal guidance of regular tapping in the monkey. J Neurosci (2015) 35(11):4635-40. doi:10.1523/JNEUROSCI.457014.2015

73. Purzner J, Paradiso GO, Cunic D, Saint-Cyr JA, Hoque T, Lozano AM, et al. Involvement of the basal ganglia and cerebellar motor pathways in the preparation of self-initiated and externally triggered movements in humans. $J$ Neurosci (2007) 27(22):6029-36. doi:10.1523/JNEUROSCI.5441-06.2007

74. Diedrichsen J, Criscimagna-Hemminger SE, Shadmehr R. Dissociating timing and coordination as functions of the cerebellum. J Neurosci (2007) 27(23):6291-301. doi:10.1523/JNEUROSCI.0061-07.2007

75. Manto M, Bower JM, Conforto AB, Delgado-Garcia JM, da Guarda SN, Gerwig $\mathrm{M}$, et al. Consensus paper: roles of the cerebellum in motor control - the diversity of ideas on cerebellar involvement in movement. Cerebellum (2012) 11(2):457-87. doi:10.1007/s12311-011-0331-9

76. Berardelli A, Rothwell JC, Thompson PD, Hallett M. Pathophysiology of bradykinesia in Parkinson's disease. Brain (2001) 124(Pt 11):2131-46. doi:10. 1093/brain/124.11.2131

77. Lozza C, Baron JC, Eidelberg D, Mentis MJ, Carbon M, Marié RM. Executive processes in Parkinson's disease: FDG-PET and network analysis. Hum Brain Mapp (2004) 22(3):236-45.

78. Colnat-Coulbois S, Gauchard GC, Maillard L, Barroche G, Vespignani H, Auque J, et al. Bilateral subthalamic nucleus stimulation improves balance control in Parkinson's disease. J Neurol Neurosurg Psychiatry (2005) 76(6):780-7. doi:10.1136/jnnp.2004.047829

79. Galvan A, Devergnas A, Wichmann T. Alterations in neuronal activity in basal ganglia-thalamocortical circuits in the parkinsonian state. Front Neuroanat (2015) 9:5. doi:10.3389/fnana.2015.00005

80. Filion M, Tremblay L, Bedard PJ. Abnormal influences of passive limb movement on the activity of globus pallidus neurons in parkinsonian monkeys. Brain Res (1988) 444(1):165-76. doi:10.1016/0006-8993(88)90924-9

81. Helmich RC, Siebner HR, Giffin N, Bestmann S, Rothwell JC, Bloem BR. The dynamic regulation of cortical excitability is altered in episodic ataxia type 2 Brain (2010) 133(Pt 12):3519-29. doi:10.1093/brain/awq315

82. Goble DJ, Coxon JP, Van Impe A, Geurts M, Doumas M, Wenderoth N, et al. Brain activity during ankle proprioceptive stimulation predicts balance performance in young and older adults. J Neurosci (2011) 31(45):16344-52. doi:10.1523/JNEUROSCI.4159-11.2011

83. Cassidy M, Mazzone $\mathrm{P}$, Oliviero A, Insola A, Tonali $\mathrm{P}, \mathrm{Di}$ Lazzaro $\mathrm{V}$, et al. Movement-related changes in synchronization in the human basal ganglia. Brain (2002) 125(Pt 6):1235-46. doi:10.1093/brain/awf135

84. Maschke M, Gomez CM, Tuite PJ, Konczak J. Dysfunction of the basal ganglia, but not the cerebellum, impairs kinaesthesia. Brain (2003) 126(Pt 10):2312-22. doi:10.1093/brain/awg230

85. Bartels AL, Balash Y, Gurevich T, Schaafsma JD, Hausdorff JM, Giladi N Relationship between freezing of gait (FOG) and other features of Parkinson's: FOG is not correlated with bradykinesia. J Clin Neurosci (2003) 10(5):584-8. doi:10.1016/S0967-5868(03)00192-9 
86. Espay AJ, Fasano A, van Nuenen BF, Payne MM, Snijders AH, Bloem BR. "On" state freezing of gait in Parkinson disease: a paradoxical levodopainduced complication. Neurology (2012) 78(7):454-7. doi:10.1212/WNL. 0b013e3182477ec0

87. Tolleson CM, Dobolyi D, Roman OC, Kanoff K, Barton S, Wylie SA, et al. Dysrhythmia of timed movements in Parkinsons disease and freezing of gait. Brain Res (2015) 1624:222-31. doi:10.1016/j.brainres.2015.07.041

88. Peterson DS, Pickett KA, Duncan R, Perlmutter J, Earhart GM. Gait-related brain activity in people with Parkinson disease with freezing of gait. PLoS One (2014) 9(3):e90634. doi:10.1371/journal.pone.0090634

89. Factor SA, Higgins DS, Qian J. Primary progressive freezing gait: a syndrome with many causes. Neurology (2006) 66(3):411-4. doi:10.1212/01.wnl. 0000196469.52995.ab

90. Goldberg G. Supplementary motor area structure and function review and hypotheses. Behav Brain Sci (1985) 8(4):567-88. doi:10.1017/S0140525X00045167

91. Goldman-Rakic PS, Bates JF, Chafee MV. The prefrontal cortex and internally generated motor acts. Curr Opin Neurobiol (1992) 2(6):830-5. doi:10.1016/ 0959-4388(92)90141-7

92. Kalaska JF, Crammond DJ. Cerebral cortical mechanisms of reaching movements. Science (1992) 255(5051):1517-23. doi:10.1126/science.1549781

93. Chafee MV, Goldman-Rakic PS. Matching patterns of activity in primate prefrontal area $8 \mathrm{a}$ and parietal area 7ip neurons during a spatial working memory task. J Neurophysiol (1998) 79(6):2919-40.

94. Abrahamse EL, Ruitenberg MF, de Kleine E, Verwey WB. Control of automated behavior: insights from the discrete sequence production task. Front Hum Neurosci (2013) 7:82. doi:10.3389/fnhum.2013.00082

95. Jenkins IH, Brooks DJ, Nixon PD, Frackowiak RS, Passingham RE. Motor sequence learning: a study with positron emission tomography. $J$ Neurosci (1994) 14(6):3775-90.

96. Wu T, Chan P, Hallett M. Modifications of the interactions in the motor networks when a movement becomes automatic. J Physiol (2008) 586(Pt 17):4295-304. doi:10.1113/jphysiol.2008.153445

97. Wu T, Hallett M. A functional MRI study of automatic movements in patients with Parkinson's disease. Brain (2005) 128(Pt 10):2250-9. doi:10.1093/brain/ awh569

98. Haaland KY, Elsinger CL, Mayer AR, Durgerian S, Rao SM. Motor sequence complexity and performing hand produce differential patterns of hemispheric lateralization. J Cogn Neurosci (2004) 16(4):621-36. doi:10.1162/ 089892904323057344

99. Newton JM, Dong Y, Hidler J, Plummer-D’Amato P, Marehbian J, AlbisteguiDubois RM, et al. Reliable assessment of lower limb motor representations with fMRI: use of a novel MR compatible device for real-time monitoring of ankle, knee and hip torques. Neuroimage (2008) 43(1):136-46. doi:10.1016/j. neuroimage.2008.07.001

100. Kapreli E, Athanasopoulos S, Papathanasiou M, Van Hecke P, Keleki D, Peeters $\mathrm{R}$, et al. Lower limb sensorimotor network: issues of somatotopy and overlap. Cortex (2007) 43(2):219-32. doi:10.1016/S0010-9452(08)70477-5

101. Wang C, Wai Y, Kuo B, Yeh YY, Wang J. Cortical control of gait in healthy humans: an fMRI study. J Neural Transm (2008) 115(8):1149-58. doi:10.1007/ s00702-008-0058-z

102. LaPointe KE, Klein JA, Konkol ML, Kveno SM, Bhatt E, DiFabio RP, et al. Cortical activation during finger tracking vs. ankle tracking in healthy subjects. Restor Neurol Neurosci (2009) 27(4):253-64. doi:10.3233/RNN-2009-0475

103. Debaere F, Swinnen SP, Beatse E, Sunaert S, Van Hecke P, Duysens J. Brain areas involved in interlimb coordination: a distributed network. [Research Support, Non-U.S. Gov't]. Neuroimage (2001) 14(5):947-58. doi:10.1006/ nimg.2001.0892

104. Taniwaki T, Okayama A, Yoshiura T, Togao O, Nakamura Y, Yamasaki $\mathrm{T}$, et al. Functional network of the basal ganglia and cerebellar motor loops in vivo: different activation patterns between self-initiated and externally triggered movements. Neuroimage (2006) 31(2):745-53. doi:10.1016/j. neuroimage.2005.12.032

105. Kandel ER, Schwartz JH, Jessell TM. Principles of Neural Science. 4 th ed. New York, NY: McGraw-Hill, Health Professions Division (2000).

106. Haggard P, Jenner J, Wing A. Coordination of aimed movements in a case of unilateral cerebellar damage. Neuropsychologia (1994) 32(7):827-46. doi:10. 1016/0028-3932(94)90021-3
107. Lo YL, Fook-Chong S, Chan LL, Ong WY. Cerebellar control of motor activation and cancellation in humans: an electrophysiological study. Cerebellum (2009) 8(3):302-11. doi:10.1007/s12311-009-0095-7

108. Bostan AC, Dum RP, Strick PL. The basal ganglia communicate with the cerebellum. Proc Natl Acad Sci US A (2010) 107(18):8452-6. doi:10.1073/pnas. 1000496107

109. Cremers J, D’Ostilio K, Stamatakis J, Delvaux V, Garraux G. Brain activation pattern related to gait disturbances in Parkinson's disease. Mov Disord (2012) 27(12):1498-505. doi:10.1002/mds.25139

110. Spraker MB, Yu H, Corcos DM, Vaillancourt DE. Role of individual basal ganglia nuclei in force amplitude generation. J Neurophysiol (2007) 98(2):821-34 doi:10.1152/jn.00239.2007

111. Cagnan H, Duff EP, Brown P. The relative phases of basal ganglia activities dynamically shape effective connectivity in Parkinson's disease. Brain (2015) 138(Pt 6):1667-78. doi:10.1093/brain/awv093

112. Song JH, Zhou PY, Cao ZH, Ding ZG, Chen HX, Zhang GB. Rhythmic auditory stimulation with visual stimuli on motor and balance function of patients with Parkinson's disease. Eur Rev Med Pharmacol Sci (2015) 19(11):2001-7.

113. Francois C, Grau-Sanchez J, Duarte E, Rodriguez-Fornells A. Musical training as an alternative and effective method for neuro-education and neurorehabilitation. Front Psychol (2015) 6:475. doi:10.3389/fpsyg.2015.00475

114. Benoit CE, Dalla Bella S, Farrugia N, Obrig H, Mainka S, Kotz SA. Musically cued gait-training improves both perceptual and motor timing in Parkinson's disease. Front Hum Neurosci (2014) 8:494. doi:10.3389/fnhum.2014.00494

115. Leow LA, Parrott T, Grahn JA. Individual differences in beat perception affect gait responses to low- and high-groove music. Front Hum Neurosci (2014) 8:811. doi:10.3389/fnhum.2014.00811

116. Leow LA, Rinchon C, Grahn J. Familiarity with music increases walking speed in rhythmic auditory cuing. Ann N Y Acad Sci (2015) 1337:53-61. doi:10.1111/ nyas. 12658

117. Bella SD, Benoit CE, Farrugia N, Schwartze M, Kotz SA. Effects of musically cued gait training in Parkinson's disease: beyond a motor benefit. Ann N Y Acad Sci (2015) 1337:77-85. doi:10.1111/nyas.12651

118. Tong Y, Forreider B, Sun X, Geng X, Zhang W, Du H, et al. Music-supported therapy (MST) in improving post-stroke patients' upper-limb motor function: a randomised controlled pilot study. Neurol Res (2015) 37(5):434-40. doi:10. 1179/1743132815Y.0000000034

119. Rojo N, Amengual J, Juncadella M, Rubio F, Camara E, Marco-Pallares J, et al. Music-supported therapy induces plasticity in the sensorimotor cortex in chronic stroke: a single-case study using multimodal imaging (fMRI-TMS) Brain Inj (2011) 25(7-8):787-93. doi:10.3109/02699052.2011.576305

120. de Dreu MJ, van der Wilk AS, Poppe E, Kwakkel G, van Wegen EE. Rehabilitation, exercise therapy and music in patients with Parkinson's disease: a meta-analysis of the effects of music-based movement therapy on walking ability, balance and quality of life. Parkinsonism Relat Disord (2012) 18(Suppl 1):S114-9. doi:10.1016/S1353-8020(11)70036-0

121. Hackney ME, Earhart GM. Effects of dance on movement control in Parkinson's disease: a comparison of Argentine tango and American ballroom. J Rehabil Med (2009) 41(6):475-81. doi:10.2340/16501977-0362

122. Hackney ME, Earhart GM. Health-related quality of life and alternative forms of exercise in Parkinson disease. Parkinsonism Relat Disord (2009) 15(9):644-8. doi:10.1016/j.parkreldis.2009.03.003

123. Hackney ME, Earhart GM. Social partnered dance for people with serious and persistent mental illness: a pilot study. J Nerv Ment Dis (2010) 198(1):76-8. doi:10.1097/NMD.0b013e3181c81f7c

124. Hackney ME, Kantorovich S, Levin R, Earhart GM. Effects of tango on functional mobility in Parkinson's disease: a preliminary study. J Neurol Phys Ther (2007) 31(4):173-9. doi:10.1097/NPT.0b013e31815ce78b

125. Hackney M, McKee K. Community-based adapted tango dancing for individuals with Parkinson's disease and older adults. J Vis Exp (2014) 9(94). doi:10.3791/52066

126. McKee KE, Hackney ME. The effects of adapted tango on spatial cognition and disease severity in Parkinson's disease. [Research Support, N.I.H., Extramural]. J Mot Behav (2013) 45(6):519-29. doi:10.1080/00222895.2013.834288

127. Duncan RP, Earhart GM. Randomized controlled trial of community-based dancing to modify disease progression in Parkinson disease. Neurorehabil Neural Repair (2012) 26(2):132-43. doi:10.1177/1545968311421614 
128. Volpe D, Signorini M, Marchetto A, Lynch T, Morris ME. A comparison of Irish set dancing and exercises for people with Parkinson's disease: a phase II feasibility study. BMC Geriatr (2013) 13:54. doi:10.1186/1471-2318-13-54

129. Hackney ME, Earhart GM. Short duration, intensive tango dancing for Parkinson disease: an uncontrolled pilot study. Complement Ther Med (2009) 17(4):203-7. doi:10.1016/j.ctim.2008.10.005

130. Marchant D, Sylvester JL, Earhart GM. Effects of a short duration, high dose contact improvisation dance workshop on Parkinson disease: a pilot study. Complement Ther Med (2010) 18(5):184-90. doi:10.1016/j.ctim.2010. 07.004

131. Westheimer O, McRae C, Henchcliffe C, Fesharaki A, Glazman S, Ene H, et al. Dance for PD: a preliminary investigation of effects on motor function and quality of life among persons with Parkinson's disease (PD). J Neural Transm (2015) 122(9):1263-70. doi:10.1007/s00702-015-1380-x

132. Kliegel M, Phillips LH, Lemke U, Kopp UA. Planning and realisation of complex intentions in patients with Parkinson's disease. J Neurol Neurosurg Psychiatry (2005) 76(11):1501-5. doi:10.1136/jnnp.2004.051268

133. Chen TL, Bhattacharjee T, McKay JL, Borinski JE, Hackney ME, Ting LH, et al. Evaluation by expert dancers of a robot that performs partnered stepping via haptic interaction. PLoS One (2015) 10(5):e0125179. doi:10.1371/journal. pone.0125179

134. Narayana S, Fox PT, Zhang W, Franklin C, Robin DA, Vogel D, et al. Neural correlates of efficacy of voice therapy in Parkinson's disease identified by performance-correlation analysis. Hum Brain Mapp (2010) 31(2):222-36. doi: 10.1002/hbm.20859

135. Brown S, Martinez MJ, Parsons LM. The neural basis of human dance. Cereb Cortex (2006) 16(8):1157-67. doi:10.1093/cercor/bhj057
136. Sacco K, Cauda F, Cerliani L, Mate D, Duca S, Geminiani GC. Motor imagery of walking following training in locomotor attention. The effect of "the tango lesson”. Neuroimage (2006) 32(3):1441-9. doi:10.1016/j.neuroimage. 2006.05.018

137. Sacco K, Cauda F, D’Agata F, Mate D, Duca S, Geminiani G. Reorganization and enhanced functional connectivity of motor areas in repetitive ankle movements after training in locomotor attention. Brain Res (2009) 1297:124-34. doi:10.1016/j.brainres.2009.08.049

138. Asanuma K, Tang C, Ma Y, Dhawan V, Mattis P, Edwards C, et al. Network modulation in the treatment of Parkinson's disease. Brain (2006) 129(Pt 10):2667-78. doi:10.1093/brain/awl162

139. Trost M, Su S, Su P, Yen RF, Tseng HM, Barnes A, et al. Network modulation by the subthalamic nucleus in the treatment of Parkinson's disease. Neuroimage (2006) 31(1):301-7. doi:10.1016/j.neuroimage.2005.12.024

140. Spraker MB, Prodoehl J, Corcos DM, Comella CL, Vaillancourt DE. Basal ganglia hypoactivity during grip force in drug naive Parkinson's disease. Hum Brain Mapp (2010) 31(12):1928-41. doi:10.1002/hbm.20987

Conflict of Interest Statement: The authors declare that the research was conducted in the absence of any commercial or financial relationships that could be construed as a potential conflict of interest.

Copyright (C) 2015 Hackney, Lee, Battisto, Crosson and McGregor. This is an openaccess article distributed under the terms of the Creative Commons Attribution License (CC BY). The use, distribution or reproduction in other forums is permitted, provided the original author(s) or licensor are credited and that the original publication in this journal is cited, in accordance with accepted academic practice. No use, distribution or reproduction is permitted which does not comply with these terms. 